\title{
THERMAL CONDUCTIVITY OF CU7.2Ni1.8Si1Cr COPPER ALLOY PRODUCED VIA SLM AND ABILITY OF THIN-WALL STRUCTURE FABRICATION
}

\author{
Jakub Mašek ${ }^{1}$, Daniel Koutný ${ }^{2}$, and Robert Popela ${ }^{3}$ \\ ${ }^{1,3}$ Institute of Aerospace Engineering; ${ }^{2}$ Institute of Machine and Industrial Design \\ Brno University of Technology \\ Technická 2, 61669 Brno, Czech Republic \\ 1 jakub.masek@vutbr.cz \\ 2 daniel.koutny@vut.cz \\ 3 popela.r@fme.vutbr.cz
}

Keywords: Additive manufacturing, SLM production accuracy, Copper alloy Cu7.2Ni1.8Si1Cr, Thin-wall structures, Thermal conductivity testing

\begin{abstract}
Selective Laser Melting (SLM) as part of the Additive manufacturing industry is a metal printing technology that is considered promising to address the thermal integrity defects of a Heat Switch - the space technology currently under development. However, no thermal conductivity data of SLMed copper alloy Cu7.2Ni1.8Si1Cr are freely available. Therefore, three parts were fabricated and tested in an experimental thermo-vacuum chamber to reveal the material thermal conductivity. The samples analogous to the Heat Switch components were: a disk with inner holes and two cylinders with thin-wall web of $0.325 \mathrm{~mm}$ and $1.625 \mathrm{~mm}$. Based on the previous experience with the copper alloy, fabrication was successfully processed with up to $5 \%$ dimensional accuracy according to CAD model. The thermal conductivity evaluation process was improved by the implementation of heat transfer by radiation and the calculated thermal conductivity of SLMed Cu7.2Ni1.8Si1Cr was 3.4 times lower than the value of bulk material AMPCOLOY 944 with a similar chemical composition.
\end{abstract}

\section{INTRODUCTION}

Selective Laser Melting (SLM) technology is a currently leading innovative manufacturing process that accelerates changes in many engineering areas - from rapid prototyping of research samples to validated components for aerospace. The benefit of printing the components layer-by-layer enables a different approach in design \& manufacturing process that can reduce costs, weight and material wasting while producing parts with the same or even better mechanical properties than the equivalent components produced conventionally by casting or forming. On the contrary the AM technology itself can create micro and macro structure defects of the created material, thermal deformations and poor surface quality $[1 ; 2]$.

Copper is one of the materials tested for the additive manufacturing, even though the set-up of process parameters is more crucial in a comparison to other materials as e.g. aluminium or steel. The copper powder exhibits low emissivity and together with a high thermal conductivity reduce an amount of absorbed energy. It has not been possible to use the SLM for pure copper production in last decade, therefore copper alloys with modified physical properties were widely investigated $[3 ; 4]$. 
A project of the Miniaturized Heat Switch (MHS) is going to implement additive technology in order to promote the current design toward an operational sample. MHS is a space component for efficient heat transfer, currently under development at the Institute of Aerospace Engineering, Brno University of Technology (BUT Brno) [5]. The copper material is therefore primarily considered to be used for a flexible thin-wall structure component produced by additive. The Institute of Machine and Industrial Design, BUT Brno developed the process parameters of a copper alloy Cu7.2Ni1.8Si1Cr, however there is a lack of the thermal conductivity data, Table 1.

\begin{tabular}{lccc}
\hline Material & Cu OFHC & AMPCOLOY 944 (bulk) & Consolidated copper alloy \\
Composition (\%) & $99.9 \mathrm{Cu}$ & $90 \mathrm{Cu} ; 7 \mathrm{Ni} ; 2 \mathrm{Si} ; 1 \mathrm{Cr}$ & $90 \mathrm{Cu} ; 7.2 \mathrm{Ni} ; 1.8 \mathrm{Si} ; 1 \mathrm{Cr}$ \\
\hline Thermal conductivity (W/m.K) & 390 & $156[6]$ & ?? \\
\hline
\end{tabular}

Table 1: Thermal conductivity comparison of Cu materials (OFHC = Oxygen Free High Conductivity)

The main objective is to design and manufacture three copper cylinders to verify the capability to produce thin-wall structures under developed process parameters and to determine the thermal conductivity of the Cu7.2Ni1.8Si1 Cr copper alloy.

\subsection{Copper as a material for Selective Laser Melting}

Pure copper and copper alloys are widely used owing to their outstanding thermal and electrical conductivities. Moreover, they have excellent mechanical properties and are low in cost. However, there are two challenges in copper fabrication via SLM: a high reflectivity of the powder and its high thermal conductivity. In fact, that means a low energy is absorbed by the irradiated powder resulting in a partial or no melting. Therefore, a greater laser power and scanning speed is required to produce consolidated parts with sufficient relative density. According to Fraunhofer Institute for Laser Technology (Germany) the minimal laser power should be more than $300 \mathrm{~W}$ [3]. A new researches were proceeded with up to $1 \mathrm{~kW}$ laser. However, due to the large energy input, an overheating, large molten pool, evaporation and oxidation of the powder can occur creating extensive porosity [4]. Therefore, a stable and continuous melting process without a possible balling effect was a subject of research by Zhang et al. [7] and Ikeshoji et al. [8] - a laser power, beam type and diameter, hatch distance, scanning speed \& strategy and an exposure time were investigated. As a result, appropriate SLM process parameters of $99.9 \%$ pure copper were found.

Pure copper fabricated via SLM can be beneficially used for heat exchangers with a low mass and a high efficient surface area. Even though the copper alloys would be easier to process by SLM, they usually contain several percent of nickel, chromium, tin or silicon that extremely reduce the thermal conductivity of the pure material. The effect of thermal conductivity reduction can be even highlighted by the SLM fabrication, as was proved in a study of Alkahari et al. [9] - the porosity has significant influence on the thermal properties of the consolidated material. Alkahari showed that the SLM fabricated steel $\mathrm{SCM}+\mathrm{Cu}+\mathrm{Ni}$ with porosity of $9 \%$ had 5.6 times lower thermal conductivity than the bulk material of the same chemical composition, as can be seen in Table 2.

\begin{tabular}{lccc}
\hline $\begin{array}{l}\text { Nature of the material } \\
\mathrm{SCM}+\mathrm{Cu}+\mathrm{Ni}\end{array}$ & Powder & Selective laser melted & Bulk \\
\hline Thermal conductivity (W/m.K) & 0.14 & 7.56 & $42.7[10]$ \\
\hline
\end{tabular}

Table 2: Thermal conductivity comparison of powder, SLM consolidated and bulk material of the same chemical composition [9] 


\subsection{Capability of copper thin-wall structures produced by SLM}

To produce a thin-wall structure by the SLM, a melt track dimension has to be controlled based on the significant influence of laser power, scan speed and laser beam diameter [7].

Thin walls of varying thicknesses (from $0.4 \mathrm{~mm}$ to $3 \mathrm{~mm}$ ) were successfully produced from C18400 copper alloy with a relative density of $96.74 \%$ under proper forming parameters [4]. Paloušek et al. [11] and investigated process parameters of $\mathrm{Cu} 7.2 \mathrm{Ni1.8Si1Cr}$ copper alloy. Klimek [12] studied the influence of SLM process parameters on the wall thickness and surface quality. Each of 100 walls was created by a different set of process parameters resulting in the surface roughness between $9.1-21.9 \mu \mathrm{m}$. The width of produced walls $(0.15$ to $0.4 \mathrm{~mm}$ ) was mostly two times higher than the designed value in CAD model, in case of designed width $0.15 \mathrm{~mm}$ the fabricated wall was $0.25 \mathrm{~mm}$ thick. In case of walls created by process parameters resulting in the best surfaces (roughness only $14-15 \mu \mathrm{m}$ ) the thicknesses of $300-360 \mu \mathrm{m}$ and relative density of $99.97 \%$ was reached. Paloušek et al. proved excellent manufacturing of the thin walls between 0.18 and $0.36 \mathrm{~mm}$ under proper process parameters and a scanning strategy "Offset filling". The resulting porosity was lower than $0.01 \%$.

\section{EXPERIMENT AND MATERIAL}

\subsection{Design of copper alloy cylinders}

Three parts were designed to verify the copper alloy CU7.2Ni1.8Si1Cr SLM process parameters and to determine the consolidated material thermal conductivity that is crucial for further development of the Miniaturized Heat Switch space project. Therefore, two cylinder demonstrators (Figure 1, a) were designed to represent the thermal conductivity of the switch (in ON and OFF mode) and to copy its external dimensions complying with a thermal test set-up. The two conductivities defined two crosssectional areas leading to a design of cylinder thin-wall web of $0.15 \mathrm{~mm}$ and $1.5 \mathrm{~mm}$ thickness, represented in Figure 1, a) by vertical tube between two horizontal baseplates. The third part (Figure 1, b) was designed as a reference disc of $56 \mathrm{~mm}$ diameter and $8 \mathrm{~mm}$ thickness. The design of all three parts is shown in Figure 1 and corresponding dimensions are stated in Table 3.

a)

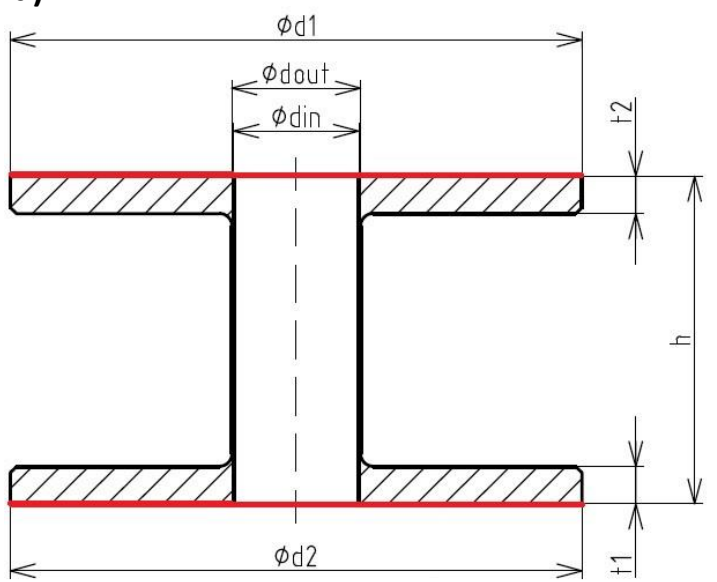

b)

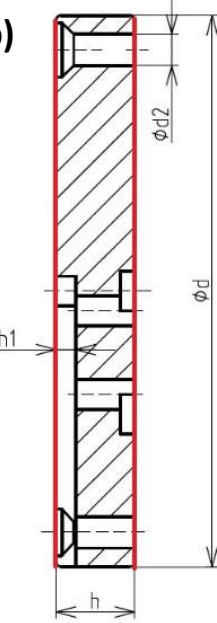

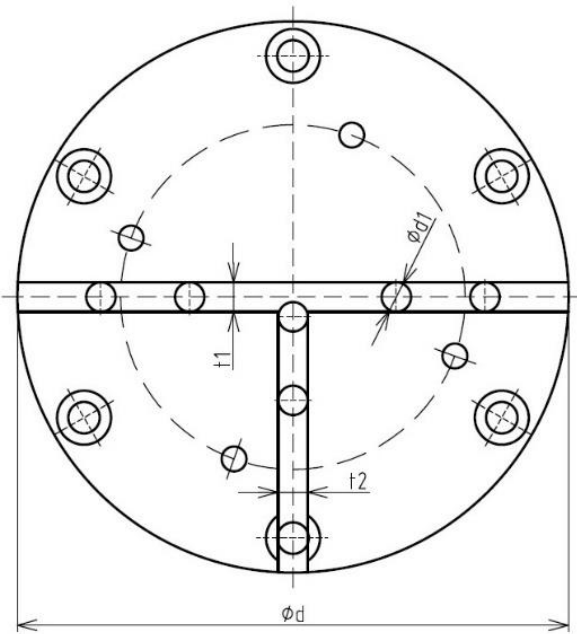

Figure 1: Design of parts for SLM production: a) cylinder (representing both ON/OFF thermal mode); b) reference disc

Cylinders Disc

\begin{tabular}{l|ccccccc|ccccccc}
\hline Dimension & $\mathrm{d} 1$ & $\mathrm{~d} 2$ & $\mathrm{din}$ & $\mathrm{d}$ out & $\mathrm{h}$ & $\mathrm{t} 1$ & $\mathrm{t} 2$ & $\mathrm{~d}$ & $\mathrm{~h}$ & $\mathrm{t} 1$ & $\mathrm{t} 2$ & $\mathrm{~h} 1$ & $\mathrm{~d} 1$ & $\mathrm{~d} 2$ \\
\hline Value $(\mathrm{mm})$ & 45.7 & 45.7 & 10 & $10.3 / 13$ & 28.2 & 3 & 3 & 56 & 8 & 3 & 3 & 2 & 3 & 3.2 \\
\hline
\end{tabular}

Table 3: Cylinder and disc dimensions for SLM production 
The outer circular surfaces of all three parts are functional to efficiently transfer the heat, therefore they were post-processed by machining (marked red in Figure 1). The components orientation was designed in the $x y$ plane with the cylinder axes along the $z$ direction.

\subsection{Copper powder}

The copper powder Cu7.2Ni1.8Si1Cr was produced by Sandvik Osprey Ltd. The powder morphology was evaluated in the study of Paloušek et al. [11] based on the laser diffraction analysis and showed mainly a spherical shape of the particles. The powder particles had a large variability in size with an average value of $22.9 \mu \mathrm{m}$ and $90 \%$ were up to $38.6 \mu \mathrm{m}$. Chemical composition defined by the vendor is shown in Table 4.

\begin{tabular}{lccccc}
\hline Element & $\mathrm{Ni}$ & $\mathrm{Si}$ & $\mathrm{Cr}$ & Others & $\mathrm{Cu}$ \\
\hline SLM powder & $7.5 \%$ & $1.8 \%$ & $0.94 \%$ & $0.085-0.095 \%$ & balance to $100 \%$ \\
\hline
\end{tabular}

Table 4: Chemical composition (wt \%) of SLM material Cu7.2Ni1.8Si1Cr

Before the component fabrication phase started, the metal powder was dried at $70^{\circ} \mathrm{C}$ for 4 hours and subsequently filled into a recoater [12]. All the samples were built on a platform (100 x $100 \mathrm{~mm})$ made of copper alloy AMPCOLOY ${ }^{\circledR} 944$ that was preheated to $120^{\circ} \mathrm{C}$.

\subsection{Additive manufacturing of the samples}

In this study, the parts were produced by the SLM $280 \mathrm{HL}$ machine equipped with a $400 \mathrm{~W}$ YLR laser with a Gaussian beam intensity distribution. The laser spot at the powder bed level has a diameter of $82 \mu \mathrm{m}$ and the maximum scanning speed can reach up to $15 \mathrm{~m} / \mathrm{s}$ [12].

All three parts were produced under the process parameters developed by the Institute of Machine and Industrial Design, BUT Brno, in particular described in the study of Paloušek et al. [11]. A powder layer thickness of $50 \mu \mathrm{m}$ was used during the production under an inert atmosphere of nitrogen. The minimum threshold of $\mathrm{O}_{2}$ concentration was $0.2 \%$ for a successful part fabrication.

The production parameters were selected on the basis of high productivity, which at the same time reaches the maximum relative density of the volume and thin-wall parts. The SLM parameters were:

- Laser power: $400 \mathrm{~W}$

- Scanning speed: $1100 \mathrm{~mm} / \mathrm{s}$

- Hatch distance: $90 \mu \mathrm{m}$

- Beam diameter: $82 \mu \mathrm{m}$

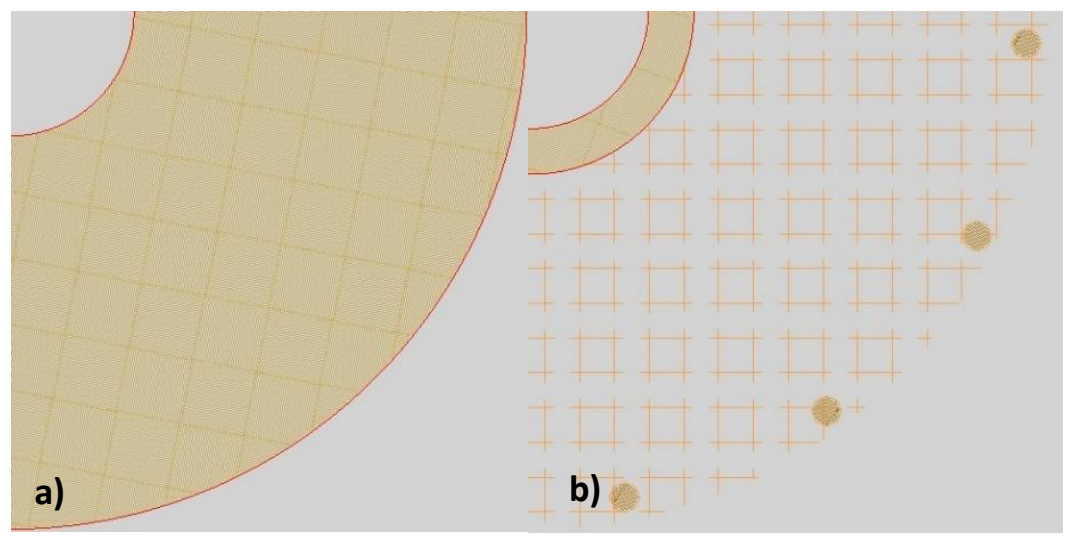

Figure 2: Scanning strategy of the laser beam: a) "chessboard" for volume parts; b) "Offset filling' for supports 
A different laser scanning strategy was set-up for the volume parts and the thin-wall structures: the web and supports. A "Chessboard" strategy of the field size $3 \times 3 \mathrm{~mm}$ and the field overlap $50 \mu \mathrm{m}$ was used for the volume parts, as shown in Figure 2, a). As a result of sequential field scanning, the thermal energy of the high power laser is distributed and therefore diminishing the residual mechanical stresses. Particularly also results into a higher relative density of the consolidated material [11]. The "Offset filling" scanning strategy was used for the support structures and the cylinder web of $0.15 \mathrm{~mm}$ thickness, Figure $2, \mathrm{~b})$. When adjusting the printing process parameters for the web and supports, it was necessary to extend the time between exposure to enable proper cooling of the thin structures.
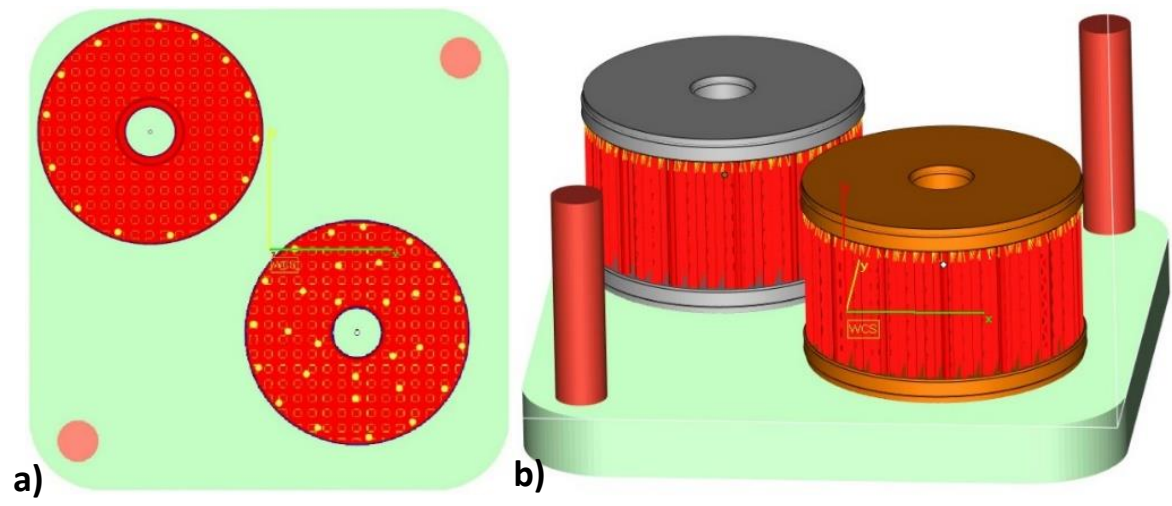

Figure 3: Generated support structures and positioning of parts on the build platform: a) top view; b) isometric view

All the three parts were printed directly on the production platform thanks to $1 \mathrm{~mm}$ layers of material added on the outer circular surfaces intended for the final machining (Figure 3, b). A high amount of support structures was generated for the cylinders with thin-wall web to hold the upper disk produced into the powder bed. Two types of the support structures were used: pins and blocks with perforated thin walls (Figure 3). The pins were added in three concentric circles (marked yellow in Figure 3, a) in the case of $0.15 \mathrm{~mm}$ web thickness to prevent any collapse during the production.

The samples were not heat treated after the completion of the building process.

The accuracy of fabricated components should be in most cases less than $5 \%$ of deviation from the 3D model dimensions to be accepted for the thermal testing. Exceptions can be evaluated individually.

\subsection{Thermal conductivity testing}

In this study, an experimental thermo-vacuum chamber, developed for space-technologies testing at the Institute of Aerospace Engineering, BUT Brno, was used for thermal conductivity measurements [13]. The testing facility can reach a vacuum level up to $20 \mathrm{~Pa}$, temperatures between $-120^{\circ} \mathrm{C}$ and $+80^{\circ} \mathrm{C}$ and supply a heat power of up to $15 \mathrm{~W}$ for heating. The testing chamber, shown in Figure 4 , is connected to supply and control systems for a vacuum, heat and temperature regulation.

Heat is generated by thermo-resistors at the Hot interface, passing through the sample to the Cold interface, that is cooled down by copper rod connected to a tank with liquid nitrogen. Cold interface temperature is regulated by reheating to a required value. Probes sense temperatures at different levels of a heat transfer path, sending the signals through a vacuum feed-through connector to a data store. In order to decrease parasitic heat leaks, thermally influenced copper components are covered by an insulation "sandwich" consisting of two Mylar foil layers and a $5 \mathrm{~mm}$ thick Upilex foam in between. The Mylar and Upilex are widely used insulation materials in space applications.

In order to verify the thermal test results, three reference parts of the same geometry as those for additive were conventionally manufactured from $99.9 \%$ OFHC copper (produced by casting, forming 
and machining). The current calibration of the test facility and the accuracy of the result evaluation process can reach up to $\pm 15 \%$ error.

$$
K=\frac{\dot{Q}}{\Delta T}
$$

On the basis of a temperature difference $\Delta T(K)$ evaluated from temperatures measured on the extremities of the sample when a heat flux $\dot{Q}(\mathrm{~W})$ passes, the thermal conductivity $K(\mathrm{~W} / \mathrm{K})$ of the specimen can be calculated as follow:
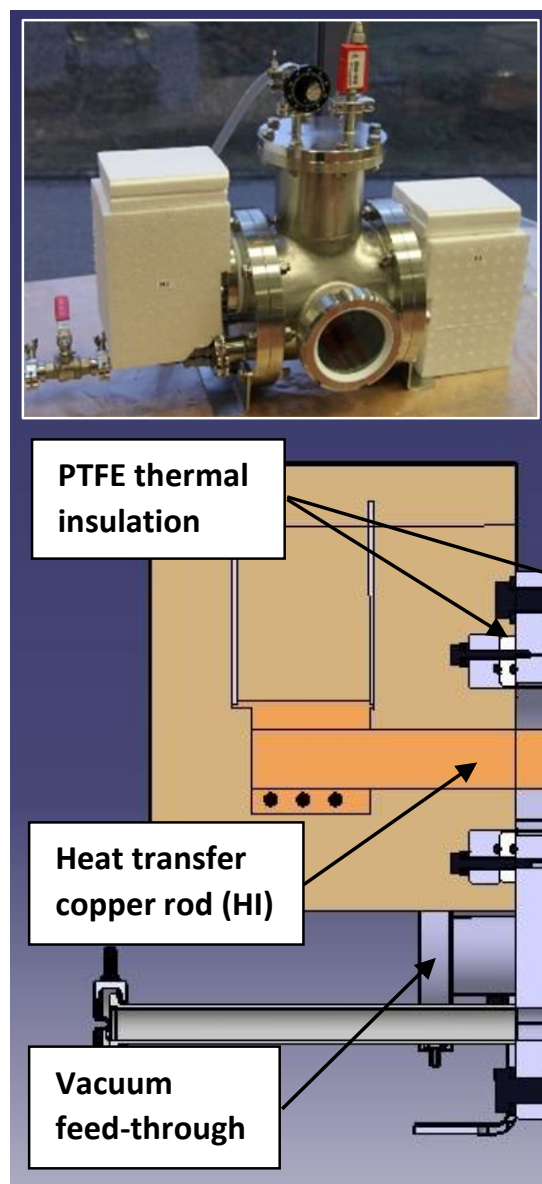
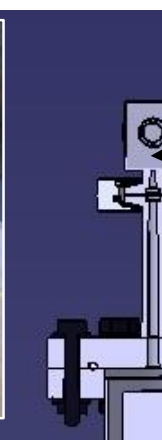

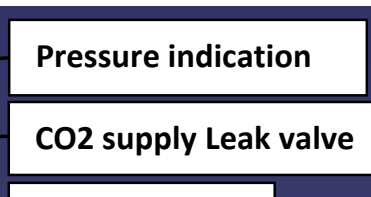

Weight ballast

Heaters

Hot Interface (HI)

SAMPLE

Cold interface (CI)

Figure 4: Experimental thermo-vacuum test chamber: a) chamber during operation; b) cross-section of 3D CAD model; Inner volume: $5.5 \mathrm{dm}^{3}$; Dimensions I/w/h: 530/344/393 mm [13]

\section{RESULTS AND DISCUSSION}

\subsection{Evaluation of samples with thin-wall structure produced by SLM}

The manufacturing of all copper samples by SLM was successful. The process parameters and especially their variation between the volume and the thin-wall parts were set up correctly since no distortion of layers nor thermal deformations after production were observed. Moreover, the amount of support structures was sufficiently rigid to hold the upper disc mass of both cylinders to disable the torsion or displacement in $x y$ plane. No macro defects of the consolidated material nor cracks were found after the final machining and removal of the supports, as can be seen in Figure 5 and 6 .

The SLM production deviations of the fabricated parts are evaluated in the Tables 5 and 6 . The dimensional accuracy compared to the 3D CAD model was in half cases up to $1 \%$ and mostly up to $5 \%$. These results are equal to the study of Paloušek et al. [11]. Exceptions in the accuracy are two types of holes in the disc part; one of diameter $3 \mathrm{~mm}$ for sensor wiring and the second of $3.2 \mathrm{~mm}$ diameter for 
bolts, both with the production deviation around $11 \%$ (Table 6). Such small holes are highly influenced by the thermal shrinkage during cooling of the material after the printing process. In case of the cylinders, another phenomenon was observed: on the lower surface of the upper discs were adhered layers of a not fully melted powder of $0.35 \mathrm{~mm}$ thickness. The dross formation always occurs when the new layers are produced into the powder bed, as was demonstrated also in studies [11] and [14].

\begin{tabular}{lccccc|c}
\hline \multirow{2}{*}{ Dimension } & & $\mathrm{d} 1$ & $\mathrm{~d} 2$ & $\mathrm{din}$ & $\begin{array}{c}\text { dout } \\
\text { Ext. disc } \varnothing\end{array}$ & $\begin{array}{c}\mathrm{t} \\
\text { Ext. disc } \varnothing\end{array}$ \\
& & Int. web $\varnothing$ & Ext. web $\varnothing$ & Web thick. \\
\hline Model of cylinders & $(\mathrm{mm})$ & 45.7 & 45.7 & 10.0 & $10.3 / 13.0$ & $0.15 / 1.5$ \\
Cylinder ON (AM) & $(\mathrm{mm})$ & 45.55 & 45.60 & 9.70 & 12.95 & 1.625 \\
Cyl.-ON deviation & $(\%)$ & $\mathbf{0 . 3}$ & $\mathbf{0 . 2}$ & $\mathbf{3 . 0}$ & $\mathbf{0 . 4}$ & $\mathbf{8 . 3}$ \\
Cylinder OFF (AM) & $(\mathrm{mm})$ & 45.65 & 45.60 & 9.70 & 10.35 & 0.325 \\
Cyl.-OFF deviation & $(\%)$ & $\mathbf{0 . 1}$ & $\mathbf{0 . 2}$ & $\mathbf{3 . 0}$ & $\mathbf{0 . 5}$ & $\mathbf{1 1 6 . 7}$ \\
\hline
\end{tabular}

Table 5: SLM production deviation of copper cylinders (measured manually)

\begin{tabular}{lcccccc}
\hline \multicolumn{1}{c}{ Dimension } & & $\begin{array}{c}\mathrm{d} \\
\text { Ext. disc } \varnothing\end{array}$ & \multicolumn{2}{c}{ t1 } & $\begin{array}{c}\mathrm{t} 2 \\
\text { Grooves width }\end{array}$ & \multicolumn{2}{c}{$\mathrm{d} 1$} & $\mathrm{~d} 2$ \\
& & Holes for screws $\varnothing$ \\
\hline Model od disc & $(\mathrm{mm})$ & 56 & 3 & 3 & 3 & 3.2 \\
Disc (AM) & $(\mathrm{mm})$ & 55.90 & 2.85 & 2.90 & 2.65 & 2.85 \\
Production deviation & $(\%)$ & $\mathbf{0 . 2}$ & $\mathbf{5 . 0}$ & $\mathbf{3 . 3}$ & $\mathbf{1 1 . 7}$ & $\mathbf{1 0 . 9}$ \\
\hline
\end{tabular}

Table 6: SLM production deviation of copper disc with internal holes (measured manually)

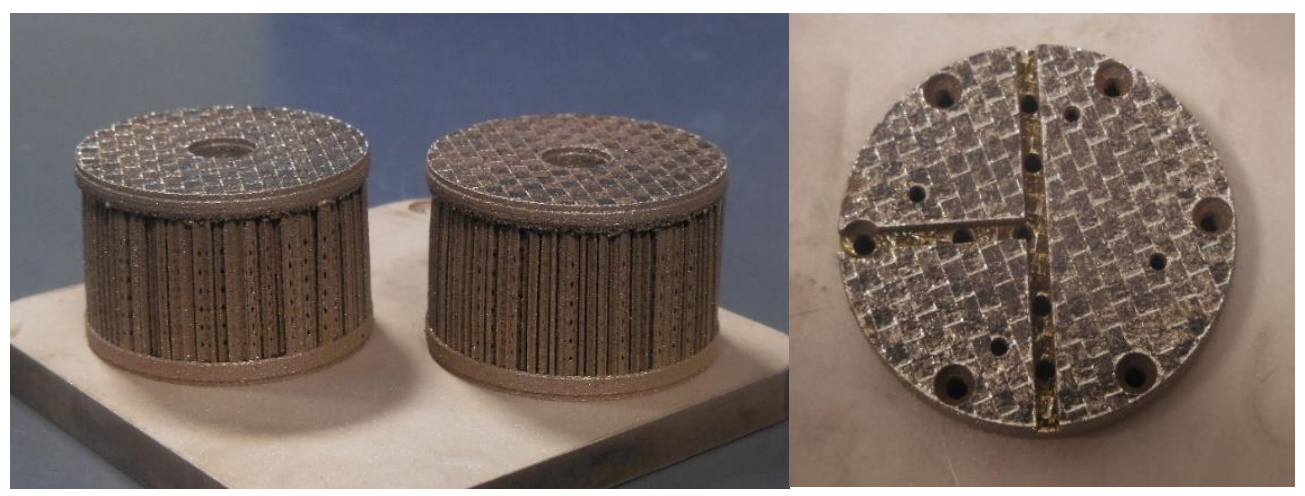

Figure 5: Cylinders and disc parts after removing of non-melted powder 


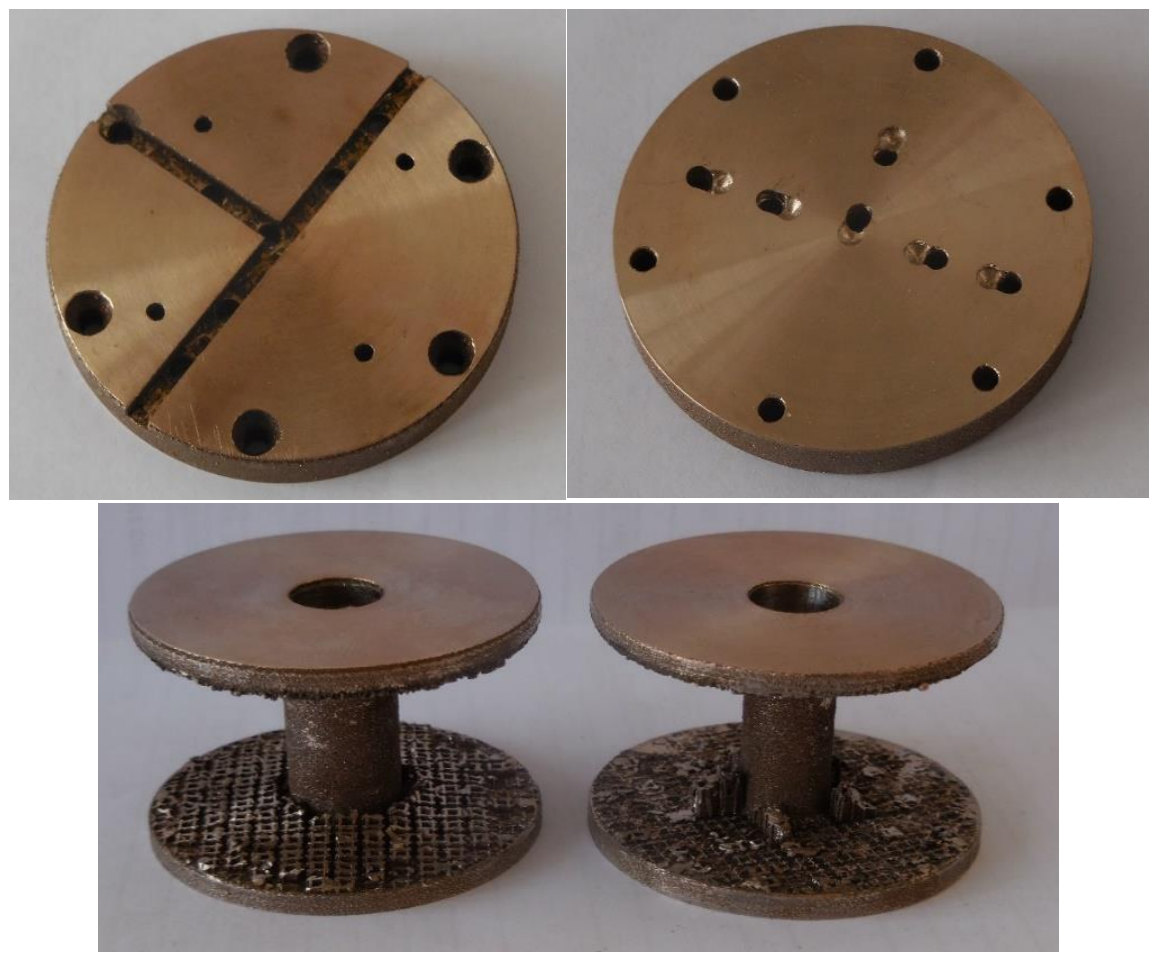

Figure 6: Cylinders and disc parts after supports removal and finishing operations by machining

For both cylinders, to determine the cross-sectional area of the thin-wall webs is crucial for the further thermal conductivity evaluation. The measured web cross-sectional area was $57.8 \mathrm{~mm}^{2}$ and $10.2 \mathrm{~mm}^{2}$, compared to the CAD design value $54.2 \mathrm{~mm}^{2}$ and $4.8 \mathrm{~mm}^{2}$ respectively (larger by $6.6 \%$ and $112.5 \%$ ). However, the SLM produced parts have a high surface roughness that can reach up to $50 \mu \mathrm{m}$ [11] and in addition, the surfaces can contain deep cavities and higher porosity. Therefore, the effective crosssectional area for the heat transfer is smaller. By counting off the theoretical correction thickness of $0.05 \mathrm{~mm}$ from the $\mathrm{d}_{\text {out }}$ and $\mathrm{d}_{\text {in }}$ dimensions, the effective area is $54.3 \mathrm{~mm}^{2}$ and $7.1 \mathrm{~mm}^{2}$ (larger by $0.2 \%$ and $47.9 \%$ respectively). The thin wall printed based on the $0.15 \mathrm{~mm}$ wall thickness in the CAD model reached the width of $0.325 \mathrm{~mm}$, the result comparable with the study of Klimek [12].

The verification of material relative density and porosity by $\mu \mathrm{CT}$ were not applied.

\subsection{Results of thermal conductivity testing}

The thermal conductivity $K(W / K)$ was evaluated for samples produced via SLM and reference samples produced conventionally from $99.9 \%$ OFHC copper. The reference samples were used to validate the current calibration status of the testing chamber. It was shown that, when evaluating the thermal conductivity of both cylinders, it is necessary to consider a radiation heat exchange between the inner circular surfaces. The radiation heat flux $\dot{Q}_{R}(\mathrm{~W})$ between two infinite parallel surfaces is as follow:

$$
\dot{Q}_{R}=\frac{S \cdot \sigma \cdot \varepsilon \cdot\left(T_{1}^{4}-T_{2}^{4}\right)}{(2-\varepsilon)}
$$

Where $S\left(m^{2}\right)$ is an area of radiation exchange surfaces with absolute temperatures $T 1$ and $T 2(K), \sigma$ is a Stefan-Boltzmann constant of $5.669 .10^{-8} \mathrm{~W} / \mathrm{m}^{2} \mathrm{~K}$ and $\varepsilon(-)$ is an emissivity of material; 0.6 for copper was used in this study. The equation (2) applies to the infinite surfaces where all radiated heat strikes the other surface. In our case where the Mylar insulation prevents any heat leakage, no additional correction coefficient for the finite surfaces was applied. 


\begin{tabular}{cccc|ccc}
\hline No. & Specimen & $\begin{array}{c}\lambda \text { teor. } \\
(\mathrm{W} / \mathrm{m} . \mathrm{K})\end{array}$ & $\begin{array}{c}\mathrm{K} \text { teor. } \\
(\mathrm{W} / \mathrm{K})\end{array}$ & $\begin{array}{c}\mathrm{K} \text { meas. } \\
(\mathrm{W} / \mathrm{K})\end{array}$ & $\begin{array}{c}\text { K error } \\
(\%)\end{array}$ & $\begin{array}{c}\lambda \text { calc. } \\
(\mathrm{W} / \mathrm{m} . \mathrm{K})\end{array}$ \\
\hline 1 & Cu 99.9\% ON mode & 390 & 0.943 & 0.888 & 5.8 & 367.2 \\
2 & Cu 99.9\% OFF mode & 390 & 0.084 & 0.077 & 8.3 & 357.7 \\
3 & Cu 90\% (AM) ON mode & $<156$ & $<0.377$ & 0.105 & 72.1 & 40.7 \\
4 & Cu 90\% (AM) OFF mode & $<156$ & $<0.034$ & $\mathrm{X}$ & $\mathrm{X}$ & $\mathrm{X}$ \\
5 & Cu 99.9 \% DISC & 390 & 120.1 & 102.1 & 15.0 & 331.5 \\
6 & Cu 90\% (AM) DISC & $<156$ & $<48.1$ & 16.1 & 66.4 & 50.2 \\
\hline
\end{tabular}

Table 7: Thermal conductivity evaluation of coper specimens produced by SLM and conventionally

Results of the thermal conductivity testing are shown in Table 7. The conductivity of reference samples, evaluated with the radiation heat correction, reached errors of $5.8,8.3$ and $15.0 \%$ over the designed values. Taking into account the current set-up of the chamber calibration together with the data evaluation process, these results are satisfactory within an error of $\pm 15 \%$. Thermal conductivity of the samples fabricated from the powder showed significant difference: $66.4 \%$ and $72.1 \%$ over the expected values (equal bulk material AMPCOLOY $944: \mathrm{K}=156 \mathrm{~W} / \mathrm{m} . \mathrm{K}$ ). The cylinder with thinner wall produced of $0.325 \mathrm{~mm}$ thickness was not tested due to the assumed too low thermal conductivity. Thereby, the average conductivity evaluated from two samples (no.3 \& 6) of the consolidated material was $45.5 \mathrm{~W} / \mathrm{m} . \mathrm{K}, 3.4$ times lower than the value of bulk material with the similar chemical composition. This result is equivalent to the research of Alkahari [9].

The evaluated conductivity of the SLM processed copper alloy $\mathrm{Cu} 7.2 \mathrm{Ni1} .8 \mathrm{Si} 1 \mathrm{Cr}$ is far from the possible value of the bulk material. One reason could be the porosity and small relative density of the produced material, even though the previous studies [11] and [12] showed good material properties with the same process parameters applied. However, macro defects in the thin wall of the cylinder can have a significant impact on the heat transfer and in addition cavities and a high surface roughness can considerably influence the effective cross-sectional area of the web and thereby the conductivity. Nevertheless, these effects do not apply to the disc component that has more favourable ratio between the cross-sectional area and the surface circumference and thus the effect of surface defects is suppressed. Unfortunately, the disk was tested without the proper Mylar thermal insulation and the measurements thereby include a heat leakage error (i.e. heat losses through convection and radiation). All in all, the real thermal conductivity of the printed copper alloy might be higher after an appropriate thermal post-processing (i.e. annealing and hot isostatic pressure - HIP) to decrease material porosity and volume defects, however it is unlikely that the conductivity would be greater than a half of the AMPCOLOY 944 value.

\section{CONCLUSION}

Based on the experiment performed, the conclusions are as follow:

1) Dimensional accuracy of the AM printed samples from Cu7.2Ni1.8Si1 Cr powder was up to $5 \%$, small holes were fabricated with deviation of approximately $11 \%$. The process parameters were selected according to the potentially lowest porosity and surface roughness.

2) Production of two cylinders with thin-wall web of 0.325 and $1.625 \mathrm{~mm}$ was successful in both cases and the amount of support structures sufficient for production without distortions, cracks or thermal deformations.

3) Quality and roughness of the surfaces after the SLM process have impact on the effective crosssectional area and thereby influence significantly the heat transfer through such cross-section. This 
phenomenon can be suppressed by designing test specimens with more favourable ratio between the cross-sectional area and the surface circumference.

4) Heat transfer by radiation was included in the thermal conductivity evaluation process in case of all cylinder samples.

5) The porosity of the SLM samples was expected to be less than $0.05 \%$ based on the previous studies, however neither the porosity nor surface roughness was measured.

6) Evaluated thermal conductivity of the SLM produced $\mathrm{Cu} 7.2 \mathrm{Ni1.8 \textrm {Si }} \mathrm{Cr}$ copper alloy parts was $45.5 \mathrm{~W} / \mathrm{m} . \mathrm{K}, 3.4$ times lower than the value of bulk material AMPCOLOY 944 with the similar chemical composition.

\section{ACKNOWLEDGEMENTS}

The research leading to these results has received funding from the MEYS under the National Sustainability Programme I (Project LO1202).

Authors would like to thank for cooperation to our colleague Ing. Marek Horák, Ph.D. from the Institute of Aerospace Engineering, BUT Brno. Our acknowledgement further belongs to the team from the Department of Reverse Engineering and Additive Technologies at the Institute of Machine and Industrial Design for the availability of additive manufacturing capabilities under the Interreg Central Europe FabLabNet Pilot 1 Program.

\section{REFERENCES}

[1] Strano, G.; Hao, L.; Everson, R. M.; Evans, K. E. (2013). Surface roughness analysis, modelling and prediction in selective laser melting. Journal of Materials Processing Tech., 213(4), 589-597.

[2] Bremen, S.; Meiners, W.; Diatlov, A. (2012). Selective Laser Melting. Laser Technik Journal, 9(2), 33-38.

[3] I.L.T. Fraunhofer (2011). SLM components made from copper alloy powder open up new opportunities. In: Powder Metalurgy Review.

[4] Zhang, D. Q.; Liu, Z. H. (2013). Investigation on forming process of copper alloys via Selective Laser Melting. In: High Value Manufacturing: Advanced Research in Virtual and Rapid Prototyping Proceedings of the 6th International Conference on Advanced Research and Rapid Prototyping.

[5] Mašek, J. (2018). Thermo-vacuum test chamber development for airborne and space equipment testing in simulated extreme conditions. In: ICAS 2018 Proceedings. 31st Congress of the International Council of the Aeronautical Sciences. Belo Horizonte, Brazil.

[6] AMPCO METAL (2018). Technical Data Sheet: AMPCOLOY 944.

[7] Zhang, D. Q.; Liu, Z. H.; Li, S.; Muzzammil, M.; Wong, C. H.; Chua, C. K. (2014). Selective Laser Melting: On the study of microstructure of K220. In: Proceedings of the 1st International Conference on Progress in Additive Manufacturing, 176-184.

[8] Ikeshoji, T.-T.; Nakamura, K.; Yonehara, M.; Imai, K.; Kyogoku, H. (2018). Selective Laser Melting of pure copper. JOM, 70(3), 396-400.

[9] Alkahari, M. R.; Furumoto, T.; Ueda, T.; Hosokawa, A.; Tanaka, R.; Abdul Aziz, M. S. (2012). Thermal conductivity of metal powder and consolidated material fabricated via Selective Laser Melting. Key Engineering Materials, 523, 244-249.

[10] Lyman, T. (1961). Metals handbook: Properties and selection of metals. 8th edition. American Society for Metals (ASM). 
[11] Palousek, D.; Kocica, M.; Pantelejev, L.; Klakurkova, L.; Celko, L.; Koutny, D.; Kaiser, J. (2018). SLM process parameters development of Cu-alloy Cu7.2Ni1.8Si1Cr. Rapid Prototyping Journal.

[12] Klimek, L. (2018). Proccess parameters development for copper thin walls manufacturing via 3D printing. Brno University of Technology, Faculty of Mechanical Engineering. Master's Thesis.

[13] Mašek, J.; Brožek, P.; Horák, M. (2017). Thermo-vacuum test chamber development for heat switch testing in simulated Martian conditions. In: Engineering Mechanics 2017, 622-625.

[14] Calignano, F. (2014). Design optimization of supports for overhanging structures in aluminum and titanium alloys by selective laser melting. Materials and Design, 64, 203-213.

\section{COPYRIGHT STATEMENT}

The authors confirm that they, and/or their company or organization, hold copyright on all of the original material included in this paper. The authors also confirm that they have obtained permission, from the copyright holder of any third party material included in this paper, to publish it as part of their paper. The authors confirm that they give permission, or have obtained permission from the copyright holder of this paper, for the publication and distribution of this paper as part of the READ 2018 proceedings.

This is an open access article distributed under the Creative Commons Attribution License which permits unrestricted use, distribution, and reproduction in any medium, provided the original work is properly cited. (CC BY 4.0 ). 